\title{
On the Variation in Size and Composition of Minke Whale (Balaenoptera acutorostrata) Forestomach Contents
}

\author{
Tore Haug and Kjell T. Nilssen \\ Norwegian Institute of Fisheries and Aquaculture \\ N-9005 Tromsø, Norway \\ Ulf Lindstrøm \\ Norwegian College of Fisheries Science, University of Troms $\varnothing$ \\ N-9037 Troms $\emptyset$, Norway \\ Hans Julius Skaug \\ Norwegian Computing Center, P.O.Box 114 Blindern \\ N-0314 Oslo, Norway
}

\begin{abstract}
Forestomach contents from 223 Northeast Atlantic minke whales (Balaenoptera acutorostrata), caught in scientific whaling operations in Norwegian and adjacent waters in 1992-94, were analysed with reference to the feeding behaviour of the species. More than half of the examined forestomachs had single-prey contents. This was particularly evident for krill (Thysanoessa spp.), herring (Clupea harengus) and capelin (Mallotus villosus), while a more frequent occurrence of gadoid species in mixed-prey forestomachs indicated that these were either less common in single-species aggregations or that they may have occasionally been eaten while pursuing the same prey as the minke whales. Within a given area, it appeared that small and large minke whales exploit the same resources, the forestomachs of the larger animals containing larger food quanta than those of smaller ones. Substantial variations in observed weights of forestomach contents suggest that minke whales usually feed during long and well defined feeding bouts separated by non-feeding periods. Krill was, however, usually found in stomachs with little contents suggesting that it may be consumed during shorter and more frequent feeding bouts. That krill was more dispersed in the area than any of the other prey items may have contributed to this. The available data may indicate that the feeding activity of minke whales is low during late night and early morning.
\end{abstract}

Key words: feeding, food, minke whale, Northeast Atlantic

\section{Introduction}

The minke whale (Balaenoptera acutorostrata) is probably the most common whale species in the Northeast Atlantic. The stock is boreo-arctic with migrations to feeding areas in the far north in spring and early summer, and southwards to breeding areas in the autumn (Jonsgård, 1966). It is obviously an important top predator on the feeding grounds where its predatory role has been studied quite thoroughly during the period May-September in 199294 in a scientific whaling program where questions concerning the feeding ecology of the species were addressed (Haug et al., MS 1992; 1995a; 1995b; 1996).
In contrast to their stenophageous krill-eating counterparts in the Antarctic (Kawamura, 1980; Bushuev, 1986; Ichii and Kato, 1991), the northeast Atlantic minke whales are rather euryphageous, feeding on a variety of prey items including both fish and crustaceans (Jonsgård, 1951; 1982; Nordøy and Blix, 1992; Haug et al., 1995a; 1995b; 1996). The 1992-94 minke whale ecology studies have produced detailed information about the prey composition in stomachs of 223 minke whales (of known sex and size) caught in five geographical subareas in Norwegian waters (Fig. 1). This permitted further analyses of several important aspects of the feeding behaviour of the species. This paper addresses the following: 
Question $i$ Do individual whales consume one particular prey species or a mixture of several prey species?

Question ii Do large and small whales consume different types of prey?

Question iii Does the prey type influence the amount of prey each whale consumes?

Question iv Do the whales show particular diurnal rhythms in feeding behaviour?

\section{Material and Methods}

\section{Sampling of whales}

Minke whales taken during scientific whaling were sampled randomly, using a sampling procedure where whales were searched for along predetermined transects, laid out randomly in each area (Haug et al., MS 1992). The transects were designed in saw-tooth patterns, mainly according to the principles used during the previous North Atlantic shipboard sightings surveys, NASS-89 (Øien, 1991).
Sets of transects were defined for all areas before the scientific whaling started, but a certain amount of flexibility was implemented in the sampling scheme, depending on factors such as ice-cover, weather conditions and observations of minke whale abundances (further details are given in Haug et al., 1996).

Chartered whaling vessels, fitted for whaling operations with crew and equipment as outlined by Christensen and Øien (1990) and in agreement with new regulations enforced by the Directorate of Fisheries in Norway, were used to catch the whales. The weapons used were the primary weapons used to kill minke whales in the Norwegian small whale fishery consisting of $50 \mathrm{~mm}$ and $60 \mathrm{~mm}$ harpoon guns fitted with $22 \mathrm{~g}$ penthrite grenade harpoons (Øen, 1995). Dead whales were brought aboard the vessel for immediate dissection and biological sampling. Of the 223 animals (121 females and 102 males) from which stomach content data were

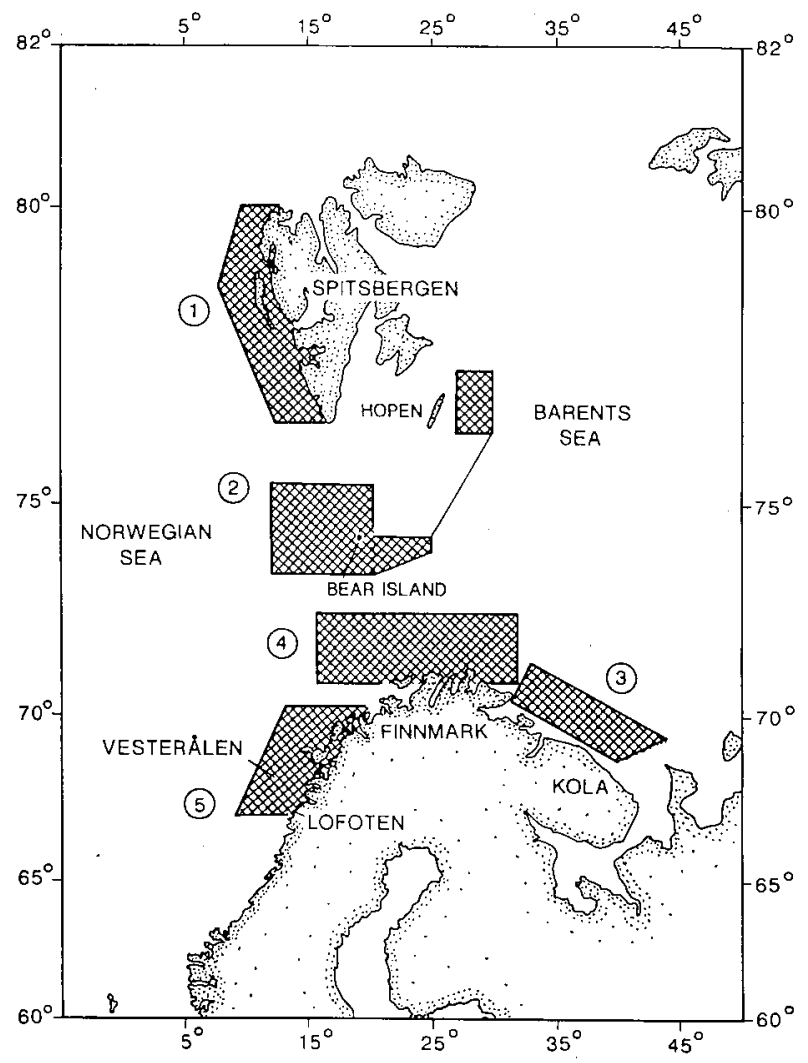

Fig. 1. Selected operational subareas where minke whales were sampled during the Norwegian scientific catch in 1992-94. 1 = Spitsbergen, 2 = Bear Island, $3=$ Kola, $4=$ Finnmark, $5=$ Lofoten-Vesterålen. 

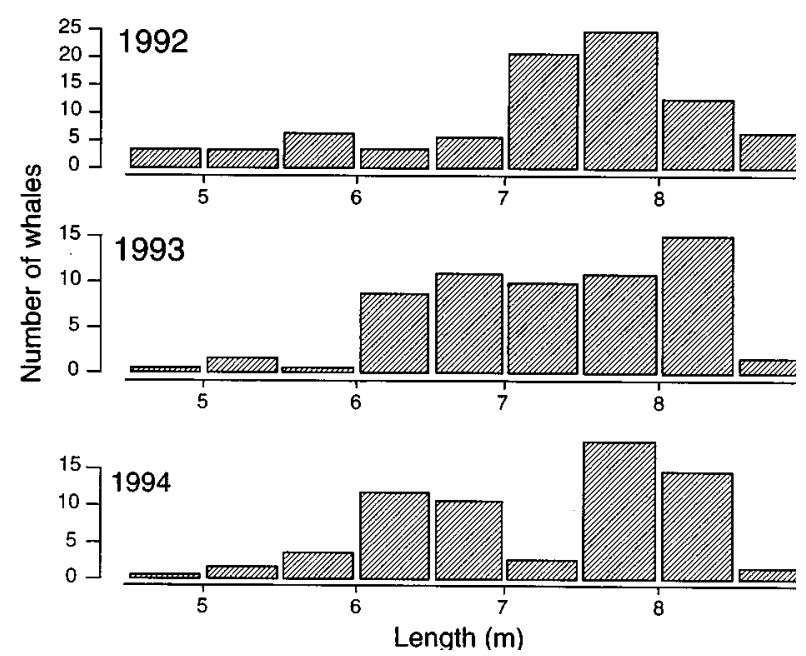

Fig. 2. Size composition (in $0.5 \mathrm{~m}$ length groups) of minke whales sampled during the Norwegian scientific catch in 1992-94.

obtained, 92, 63 and 68 were taken in 1992 (JulyAugust), 1993 (May-September) and 1994 (MaySeptember), respectively. The whales ranged in total body length from 442 to $883 \mathrm{~cm}$ (Fig. 2). Males and females were pooled in all analyses.

\section{Analyses of stomach contents}

The complete digestive tract was cut out of the whale as soon as possible (1-3 hours post mortem). Minke whale stomachs consist of a series of four chambers (Olsen et al., 1994b). Experience from pilot studies suggested that sampling from the first chamber (the forestomach) would give sufficient data to evaluate the diet of the animals (Nordøy and Blix, 1992). Therefore, only contents from this stomach chamber were used in the present analyses. The on-board and laboratory treatment of the forestomach contents were as described in detail by Haug et al. (1995a).

From the forestomach contents, fish otoliths were collected and identified to the lowest possible taxon, preferably to species (Breiby, 1985; Härkönen, 1986). The total numbers of each fish species were determined by adding the number of fresh specimens, the number of intact skulls and half the number of free otoliths. Random subsamples of otoliths were measured, and otolith length - fish length/weight correlations were used to estimate the original fish weight. Erosion of otoliths, which is a problem in studies of seal stomachs (Pierce and Boyle, 1991), was not important in this study as the analyses were restricted to the contents of the forestomach, where digestive glands are completely absent and no gastric acids are produced (Olsen et al., 1994b).

For the crustacean contents, the total weight and the number of individuals were recorded for each species in subsamples, and this was used to obtain crude estimates of the numerical contribution of each prey species. Known mean weights of fresh crustaceans were used to obtain crude estimates of the original biomass of the crustaceans eaten by each whale.

Several feeding indices are used commonly in stomach analyses of top predators (Hyslop, 1980; Pierce and Boyle, 1991). In this presentation, only the relative contribution of each prey species to the total diet expressed in terms of calculated fresh weight $(\mathrm{kg})$, was used. The stomach contents were originally divided into 12 species/taxa (Haug et al., 1995a; 1995b; 1996). Based on their dietary importance and in order to simplify the statistical exercises, we have chosen to combine these species/taxa into 7 new categories (see Table 1), when addressing questions $i$ and $i$ above.

\section{Statistical methods}

When addressing question $i$, any food item which contributed to more than $1 \%$ of the total biomass in the forestomach was classified as a valid prey for a given whale.

When addressing question ii and iii, the following simplifying assumption (Assumption 1) had to be made that -the whale forestomach contained only one type of prey.

Assumption 1 was not perfectly consistent with the data, and in practise each forestomach had to be classified according to which prey species was dominant. In the analysis of question iii, the effect of relaxing Assumption 1 was studied. The different prey species were denoted by $A_{1}, \ldots \ldots, A_{k}$. Following Haug et al. (MS 1992) the expression $\mathrm{T} \in\{1, \ldots, \mathrm{k}\}$ was let to indicate the type of prey that the forestomach contained, for instance $T=2$ meant that the whale had eaten $A_{2}$.

While addressing question $i$, a $700 \mathrm{~cm}$ limit was used as an arbitrary distinction between large and small whales. Although maturity does not constitute the rationale for the choice of $700 \mathrm{~cm}$, it is noted that female and male northeast Atlantic minke 
TABLE 1. Definition of the prey categories used in the statistical analyses of Questions $i$ and iii. (see text for further explanation).

\begin{tabular}{|c|c|}
\hline Prey category & Original species/taxa included \\
\hline 0 -group fish & $\begin{array}{l}\text { 0-group herring (Clupea harengus) } \\
\text { 0-group gadoids }\end{array}$ \\
\hline Pelagic & $\begin{array}{l}\text { Sand eels (Ammodytes sp.) } \\
\text { Saithe (Pollachius virens) }\end{array}$ \\
\hline Capelin & Capelin (Mallotus villosus) \\
\hline Cod + haddock & $\begin{array}{l}\text { Cod (Gadus morhua) } \\
\text { Haddock (Melanogrammus aeglefinus) }\end{array}$ \\
\hline Herring & Herring (Clupea harengus) \\
\hline Plankton & $\begin{array}{l}\text { Krill (Thysanoessa spp.) } \\
\text { Various crustaceans }\end{array}$ \\
\hline Others & Various other fish species \\
\hline
\end{tabular}

whales mature at approximate body lengths of 715 and $675 \mathrm{~cm}$, respectively (Christensen, 1981). The aim here was to test the hypothesis:

\section{$\mathrm{H}$ : Large $(>7 \mathrm{~m})$ and small $(<7 \mathrm{~m})$ whales have the same feeding preference pattern.}

If $\mathrm{M}$ indicates whether the whale is large $(M=$ 1) or small $(M=2)$, the hypothesis $H$ can then be formulated as $T$ and $M$ being statistically independent, and tested using the test for independence in a two-way contingency table (Dobson, 1983). Defining $X_{i j}$ as the number of whales for which $T=i$ and $M=j$, the Pearson statistic is defined as:

$$
x^{2}=\sum_{i=1}^{k} \sum_{j=1}^{2} \frac{\left\{X_{i j}-\hat{X}_{i j}\right\}^{2}}{\hat{X}_{i j}}
$$

where $\hat{X}_{i j}$ is the expected value of $X_{i j}$ given that $\mathrm{H}$ is true. When $\mathrm{H}$ is true, $x^{2}$ has an approximate chi-square distribution with $k-1$ degrees of freedom. Thus the p-value for the test is calculated as:

$$
\mathrm{p}-\text { value }=\operatorname{Pr}\left\{x^{2}>x^{2} \text { obs }\right\}
$$

where $x_{o b s}^{2}$ is the test statistic calculated from the observations.

When addressing question iii, we let $V_{t}$ be the weight of the contents of a whale forestomach at time $t$. As t varies, $V_{t}$ follows a cyclical pattern, where it decreases as digestion proceeds, and in- creases rapidly when the whale is having a meal. In addition to this variation, it is reasonable to believe that $V_{t}$ also depends on factors such as the size of the whale and the type of prey.

Each whale was sampled at a random time point in its feeding cycle, with the observed value of $V_{t}$ denoted by $V$ and let $l$ be the length of the whale. In the following discussion $V$ is conditional on the values of $l$ and $T$. A plausible model (Model 1) is:

$$
V=\mu(T, l) \times Z
$$

where $\mu(T, l)$ is a function and $Z$ is a positive random variable with expectation $E(Z)=1$. Thus $E(V)=\mu(T, l)$, and the variance of $V$ is proportional to $\mu^{2}(T, l)$. The random variable $\mathrm{Z}$ represents the fact that the whale is caught at a random time point in its feeding cycle. A possible choice of $\mu$ (Model 2) is:

$$
\log \{\mu(T, l)\}=\beta \times \log (l)+a_{T}, T=1, \ldots, k
$$

where $\beta$ and $a_{1}, \ldots, a_{k}$ are regression parameters with $a_{1}, \ldots ., a_{k}$ belonging to the species $A_{1}, \ldots ., A_{k}$. We remark that in this model $E(V)$ is proportional to $l^{\beta}$. From mathematical considerations it is expected that $\beta=3$, since the weight of the whale is approximately proportional to the cube of its length (Horwood, 1990). On a log scale the model (Model 3) for $V$ becomes:

$$
\log (\mathrm{v})=\beta \times \log (l)+\alpha_{T}+\log (\mathrm{Z})
$$


which can be fitted by standard linear regression methods (Dobson, 1983).

The hypotheses to be tested are that there is no effect of whale size:

$$
H_{\text {size }}: \beta=0
$$

or effect of prey type:

$$
H_{\text {type }}: \alpha_{1}=\ldots .=\alpha_{k}
$$

To test $H_{\text {size }}$ the submodel (Model 4) is fitted as:

$$
\log \{\mu(T, l)\}=\alpha_{T}
$$

and compare the residual sum of squares (RSS) here to the RSS of the full Model 2. The RSS is a measure of how well the model fits the data. Similarly, to test $H_{\text {type }}$ the Model 5 fit is:

$$
\log \{\mu(T, l)\}=\beta \times \log (l)+\alpha
$$

where $\alpha$ is the common value of the $\alpha_{T}$.

To remove Assumption 1 it is defined that $d=\left(d_{1}, \ldots, d_{k}\right)$, where $d_{i}$ is the relative amount of $A_{i}$ in the stomach. A reasonable model is:

$$
\log \{\mu(T, l)\}=\beta \times \log (l)+\sum_{i=1}^{k} \alpha_{i} \times d_{i}
$$

Note that if Assumption 1 is satisfied, i.e. that only one $d_{i}$ is non zero, then this model reduces to the Model 2.

To investigate whether the volume of the forestomach contents of the whales varies systematically during a $24 \mathrm{hr}$ period (question iv), the first step was to plot the stomach volume against time of capture for all whales in the sample. In addition, a nonparametric trend curve for the forestomach volume data was plotted, using the local regression routine "loess" in S-plus (Chambers and Hastie, 1993). Error bounds (95\% confidence limits) were added to facilitate evaluation of possible significant deviations of the trend curve from the mean volume of all the stomachs.

All computations were carried out using the statistical software S (Becker et al., 1988).

\section{Results}

Question $i$ Do individual whales consume one particular prey species or a mixture of several prey species?

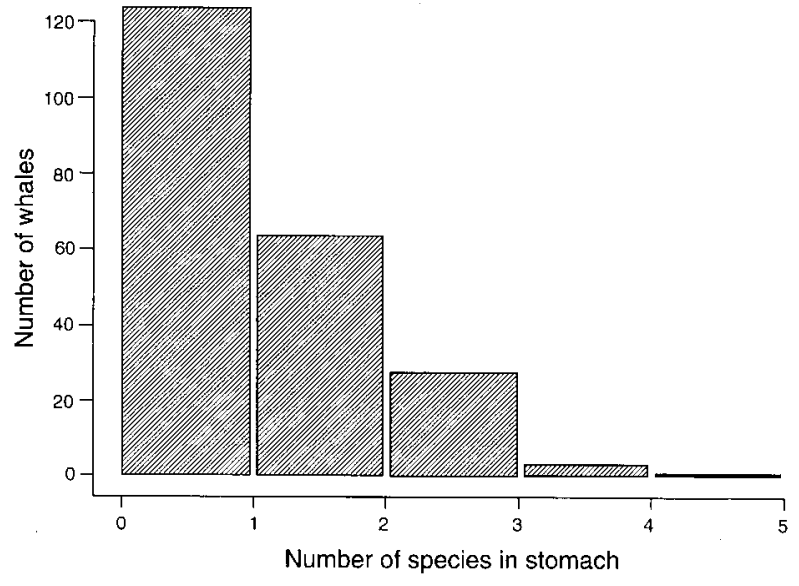

Fig. 3. Distribution of the number of different prey species found in each forestomach of minke whales sampled during the Norwegian scientific catch in 1992-94. To be counted as present in a forestomach, a species had to constitute more than $1 \%$ of the total weight of the forestomach contents.

Using $1 \%$ of the total biomass in a given stomach as the lower limit for which an observed prey item should be considered valid, it appears that approximately $56 \%$ of the whales had only one prey category in their forestomach (Fig. 3). In the remaining $44 \%$, species from either 2,3 , 4 or 5 prey categories were found simultaneously in the individual stomachs.

Of the single-prey forestomachs, 39\%, 35\% and $18 \%$ contained krill, herring (also 0 -group) or capelin, respectively. The remaining $8 \%$ included either sand-eels or gadoids (saithe, cod or haddock).

Question ii Do large and small whales consume different types of prey?

Table 2 shows the values of $X_{i j}$ for $i \in\{1, \ldots ., 6\}$ and $j \in\{1,2\}$ and the corresponding expected values

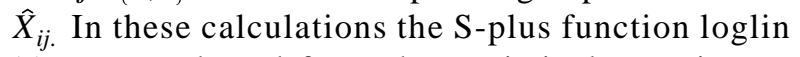
( ) was used, and from the statistical tests it was found $x^{2}=4.16$, which gives a $\mathrm{p}$-value $=0.53$. Thus the hypothesis $H$ was not rejected. Also, $H$ was tested within the five sampling areas Spitsbergen, Bear Island, Finnmark, Kola, Lofoten-Vesterålen (Fig. 1). The hypothesis was not rejected in any of these areas.

Question iii Does the prey type influence the amount of prey each whale consumes? 
TABLE 2. Testing potential heterogeneity in feeding habits among small $(<7 \mathrm{~m})$ and large $(>7 \mathrm{~m})$ minke whales: Observed and expected (in parentheses) values of $X_{i j}$ to be used in the calculations of the applied Pearson statistics (see text for further explanation). Prey categories are as explained in Table 1.

\begin{tabular}{|c|c|c|c|c|c|c|}
\hline & \multicolumn{6}{|c|}{ Prey categories } \\
\hline & $\begin{array}{c}\text {-group } \\
\text { fish }\end{array}$ & Capelin & $\begin{array}{c}\text { Cod+ } \\
\text { Haddock }\end{array}$ & Herring & Pelagic & Plankton \\
\hline Small whales & $13(12)$ & $19(18)$ & $22(24)$ & 43 (39) & $8(8)$ & $38 \quad(43)$ \\
\hline Large whales & $5 \quad(6)$ & $9(10)$ & $15(13)$ & $17(21)$ & 4 (4) & $29(24)$ \\
\hline
\end{tabular}

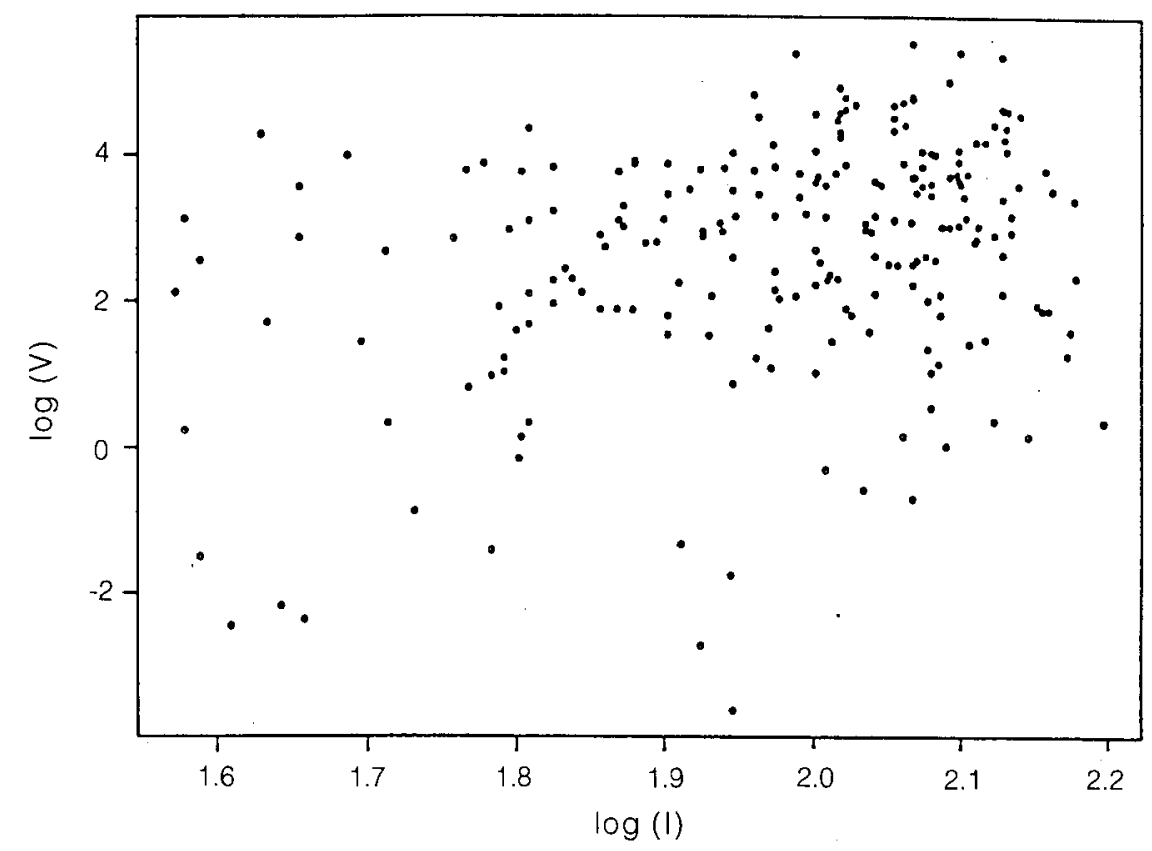

Fig. 4. Log-transformations of observed minke whale forestomach content weights $(\log (\mathrm{V}))$ plotted against $\log$ transformations of whale lengths $(\log (l))$. These are data from whales sampled during the Norwegian scientific catch in 1992-94.

As seen from Fig. 4, a linear relation between the log-transformations of observed minke whale forestomach content weights and the corresponding whale lengths seemed plausible. The figure serves as a motivation for including the term $\log (l)$ in Model 2. The significance of the term $\log (l)$ was also clear from Table 3 , where the estimate of $\beta$ is $3.50 \pm 0.71$.

From Fig. 5, a box plot of observed forestomach contents weights $(V)$ for the different prey categories, it is seen that $V$ tends to be large for cod+haddock and for herring, and small for plankton.

Table 3 shows the estimates of the parameters in the linear Model 3 together with their standard deviations. The estimated value $\hat{\beta}=3.5$ is relatively close to the value $\beta=3$ which is what was expected from mathematical considerations. It is further seen that the prey categories cod+haddock and herring have the largest estimated $\alpha$ values and that plankton has the smallest $\alpha$ value. These findings are in correspondence with Fig. 5. 


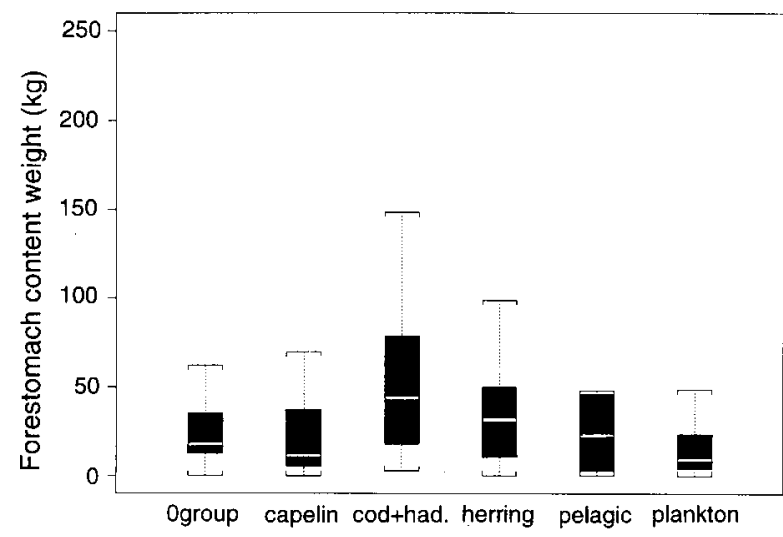

Fig. 5. Boxplot of minke whale forestomach weights $(V)$ stratified by prey categories. The dark areas cover $50 \%$ of the observations, and the white bars represent the medians of the observation. These are data from whales sampled during the Norwegian scientific catch in 1992-94.

To test the hypothesis $H_{\text {size }}$ the RSS for the Model in equation 4 was compared to the RSS of the full Model 2. The p-value for this test was found to be $1.5 \times 10^{-6}$, so the hypothesis, that there is no effect of whale length on meal size, was very clearly rejected. Similarly $H_{\text {type }}$ was tested by comparing RSS for the Model 5 to RSS of the full Model 2. This yielded a p-value of $8.8 \times 10^{-5}$, which also clearly rejects the hypothesis that there was no effect of prey type on meal size. Here, p-values and parameter estimates were calculated using the $\mathrm{S}$ function $\operatorname{lm}($ ).
It should be pointed out that the residuals from the fit of the Model 3 did not appear to be normally distributed. This fact has no effect on the estimation of parameters, since the model was not based on normal assumptions. However, the calculated p-values were only exact when $\log (Z)$ in Model 3 had a normal distribution, but for both $H_{\text {size }}$ and $H_{\text {type }}$ the rejection was so clear that the deviation from normality would likely have no effect on the conclusion.

Finally, the parameters of Model 6 were estimated. Recall that this model is a generalization of the model fitted above in the sense that Model 6 does not rely on Assumption 1, i.e., that the whale stomach contains only one type of prey. The parameters in Model 6 have the same interpretation as the parameters in Model 2. Table 3 shows the estimated parameters for the Model 6. It is seen that except for the category cod+haddock, which has a higher value of in Model 6 than in Model 3, there are very small differences between the two models. This suggests that the assumption that whale stomachs contain only one type of prey is not critical for the analysis.

Question iv Do the whales show particular diurnal rhythms in feeding behaviour?

The observed total content volumes in the forestomachs varied substantially without clear evidence of a diurnal rythm (Fig. 6). However, when comparing the trend curve with the mean volume of all forestomachs $(33.2 \mathrm{l})$, the forestomach vol-

TABLE 3. Testing the effect of minke whale length and prey type (as described in Table 1) on forestomach content size: Estimation of the parameters $\alpha$ and $\beta$ in Model 3 and in Model 6 , the values for the latter given in parentheses. S.D. $=$ standard deviation. See text for further explanations.

\begin{tabular}{|c|c|c|c|c|c|c|c|}
\hline & \multicolumn{7}{|c|}{ Estimates of $\alpha$} \\
\hline & $\beta$ & $\begin{array}{l}\text { 0-group } \\
\text { fish }\end{array}$ & Capelin & $\begin{array}{c}\text { Cod+ } \\
\text { Haddock }\end{array}$ & Herring & Pelagic & Plankton \\
\hline Estimate & $\begin{array}{c}3.50 \\
(3.46)\end{array}$ & $\begin{array}{c}-4.32 \\
(-4.43)\end{array}$ & $\begin{array}{c}-4.67 \\
(-4.54)\end{array}$ & $\begin{array}{c}-3.33 \\
(-2.85)\end{array}$ & $\begin{array}{c}-3.97 \\
(-3.94)\end{array}$ & $\begin{array}{c}-4.35 \\
(-4.47)\end{array}$ & $\begin{array}{c}-4.77 \\
(-4.72)\end{array}$ \\
\hline S.D. & $\begin{array}{c}0.71 \\
(0.71)\end{array}$ & $\begin{array}{c}1.42 \\
(1.44)\end{array}$ & $\begin{array}{c}1.43 \\
(1.44)\end{array}$ & $\begin{array}{c}1.40 \\
(1.42)\end{array}$ & $\begin{array}{c}1.43 \\
(1.45)\end{array}$ & $\begin{array}{c}1.44 \\
(1.45)\end{array}$ & $\begin{array}{c}1.40 \\
(1.41)\end{array}$ \\
\hline
\end{tabular}




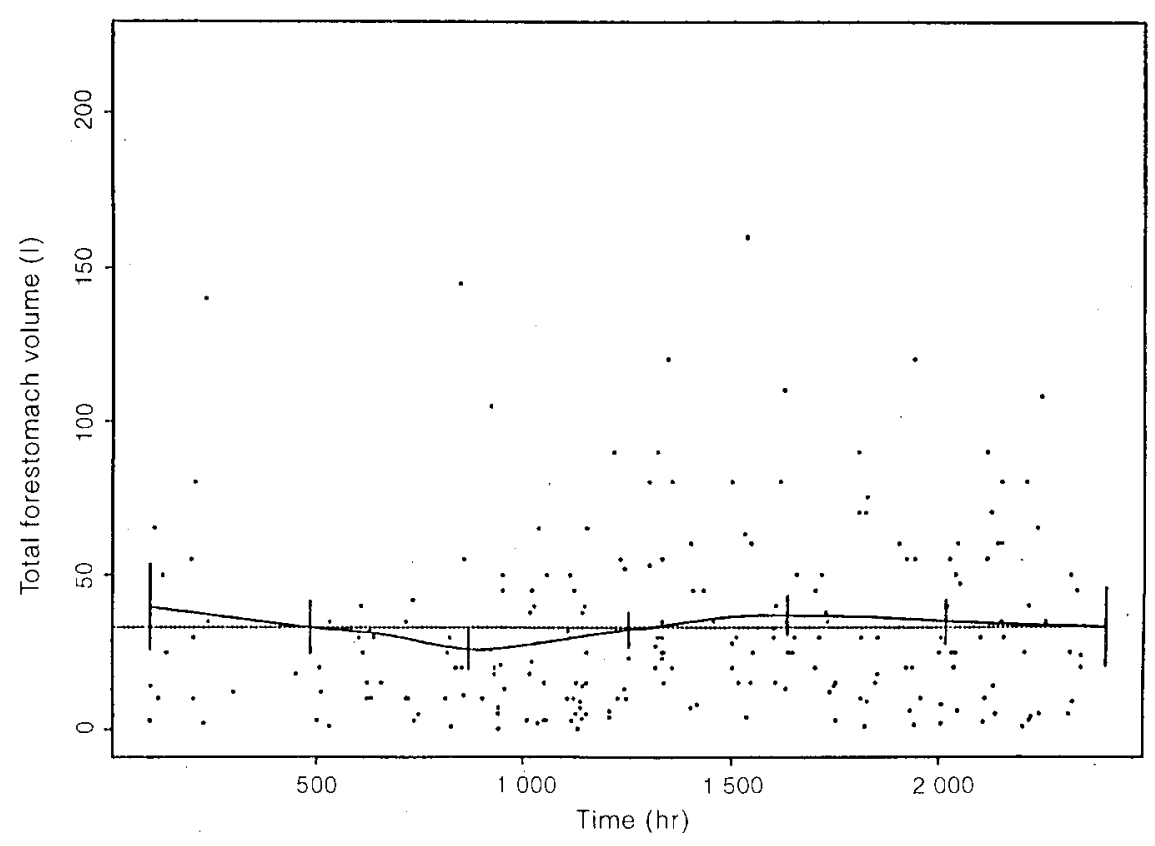

Fig. 6. Plot of observed forestomach volumes against time of capture (local time $=\mathrm{GMT}+2 \mathrm{hrs}$ ) for the 223 minke whales sampled during the Norwegian scientific catch in 1992-94. A nonparametric trend curve (solid line) with $95 \%$ confidence limits (vertical bars) as well as the mean value for all forestomach values (dotted line) is indicated.

umes tended to decrease during the late night and early morning, followed by an increase between $0800 \mathrm{hr}$ and $1600 \mathrm{hr}$. However, this trend only explains a small part of the total variation in the data, since only the observed minimum around $0800 \mathrm{hrs}$ in the morning deviates significantly from the $33.2 l$ mean volume.

\section{Discussion}

The prominence of krill, herring and capelin in the single-prey forestomachs emphasizes the importance of these species in the diets of northeast Atlantic minke whales (see also Haug et al., 1995a; 1995b; 1996). Presumably, minke whales are able to find and feed on single-species aggregations of these species, although there is a possibility that they may be reluctant to feed upon krill when alternative prey is available (Skaug et al., 1997). The occurrence of gadoid species in a few single-prey forstomachs shows that these species may also be target species for feeding minke whales. Their more frequent occurrence in mixed-prey stomachs may, however, indicate that they are, at least occasionally, eaten while pursuing the same prey as the minke whales. Relatively dense schools of gadoids (cod, haddock and saithe) may occur in FebruaryMay in their spawning areas along the Norwegian coast south of Finnmark (Bergstad et al., 1987). Probably with the exception of young $(<45 \mathrm{~cm}$ in total length) saithe, none of these gadoid species are known to occur in single-species aggregations outside the spawning season (Olav Rune Godø, Institute of Marine Research, Bergen, Norway, pers. comm., 1996). Except in the area Lofoten/ Vesterålen in May, it is thus unlikely that minke whales taken in the scientific whaling operations could have had any oportunity to pursue spawning aggregations of gadoids. The unavailability of dense single-species gadoid aggregations may thus also have contributed to the low occurrence of cod, haddock and saithe in single-prey forestomachs.

The size composition of whales taken randomly in the 1992-94 scientific catch operations resembles that observed in the commercial catches around 1980 , i.e. with relatively small number of whales smaller than $6 \mathrm{~m}$ in total body length (Øien, 1988). When comparing large $(>7 \mathrm{~m})$ and small $(<7 \mathrm{~m})$ whales, there was no statistical evidence of sizedependent differences in feeding patterns. This was true both when the different sampling areas were treated separately and when all data were pooled. Whales of all ages, therefore, appear to exploit the same resources within a given area. 
The observed size of minke whale forestomach contents seems to be related to both the size of the whale and the prey type eaten. There was a considerable variation in the observed meal sizes, with an apparent increase occurring approximately proportional to the cube of the length of the whale. The latter could also be expected from simple mathematical considerations since bigger whales have bigger stomach volumes. The feeding behaviour tended towards large, well defined meals rather than more continuous feeding of smaller quanta. The latter may, however, apply to minke whales feeding on plankton (which was almost exclusively krill). In general, minke whale forestomach contents consisting of plankton tended to be small while those consisting of cod+haddock and herring were the largest. There is no evidence of large differences in the digestibility of the various prey items found in minke whale stomachs (Nordøy et al., 1993; Mårtensson et al., 1994; Olsen et al., 1994a; $1994 b)$, nor are there any arguments for quick passage of krill through (and evacuation from) the minke whale gastrointestinal tract than of other food items (Erling S. Nordøy, Dept. of Arctic Biology, University of Troms $\emptyset$, pers. comm.). The structure of the exoskeleton (including both wax esters and chitin) of the krill might, however, result in a delayed passage of this prey item, and it has been proposed that the multi-chambered stomach of minke whales is an adaption to increase passage time of such complex structures (Olsen et al., 1994b). Thus, the reasons for the generally small contents of krill in forestomachs must probably be sought elsewhere. It is known that under favourable feeding conditions, krill-eating Antarctic minke whales usually have one single daily peak feeding period (Bushuev, 1986; Ichii and Kato, 1991). This results in large daily variations in the amounts of forestomach contents, while in areas with less stable and more dispersed krill concentrations the differences in daily feeding activity is much smaller. The present observations appear to be similar to the latter, and could indicate that the concentrations of krill in patches pursued by the northeast Atlantic minke whales may have been low and insufficient for the whales to satiate themselves by filling their forestomachs with a large meal once per day.

Although the observed forestomach volumes varied substantially during a $24 \mathrm{hr}$ period, the available data may present a weak indication that the feeding activity of the minke whales is relatively low at late night and early morning. Interestingly, recent results from tracking of minke whales, tagged with VHF-radio transmitters, off the coast of North Norway yielded significantly lower frequencies of surfacing rates during the night than during the day (Folkow and Blix, 1993). These observations may support a view that the minke whales rest during night and allocate their feeding activities to daytime hours.

\section{Acknowledgements}

Sincere thanks are extended to field assistants and crews on board the chartered whaling vessels Ann Brita, Asbjфrn Selsbane, Brandsholmbфen, Havliner, Leif Junior, Nybræna, Rango and Reinebuen. Assistance was received also from N. Øien in transect constructions and from G. L. Andersen, I. Berg, V. Frivoll, L. Svensson, L. Lindblom in laboratory treatment of whale stomach contents. Dr E.S. Nord $\varnothing$ y provided useful comments to the manuscript, and R.T. Barrett improved the English. The ecological studies of Northeast Atlantic minke whales were supported economically by the Norwegian Council of Research, projects 104499/110 and 108146/110.

\section{References}

BECKER, R., J. CHAMBERS and A. WILKS. 1988. The new S language. Wadsworth and Brooks, Pacific Grove, California.

BERGSTAD, O.A., T. JØRGENSEN and DRAGESUND, O. 1987. Life history of the gadoid resources of the Barents Sea. Fish. Res., 5: 119-161.

BREIBY, A. 1985. Otolitter fra saltvannsfisker i Nord Norge. Tromura Naturvitensk. 53: 1-30.

BUSHUEV, S.G. 1986. Feeding of minke whales, Balaenoptera acutorostrata, in the Antarctic. Rep. Int. Whal. Comm., 36: 241-245.

CHAMBERS, J. and T. HASTIE. 1993. Statistical models in S. Chapman and Hall, New York.

CHRISTENSEN, I. 1981. Age determination of minke whales, Balaenoptera acutorostrata, from laminated structures in the tympanic bullae. Rep. Int. Whal. Comm., 31: 245-253.

CHRISTENSEN, I. and N. ØIEN. 1990. Operational patterns of the Norwegian minke whale fishery. Rep. Int. Whal. Comm., 40: 343-347.

DOBSON, A. J. 1983. An Introduction to Statistical Modelling. Chapman and Hall, New York.

FOLKOW, L.P. and A.S. BLIX. 1993. Daily changes in surfacing rates of minke whales (Balaenoptera acutorostrata) in Norwegian waters. Rep. Int. Whal. Comm., 43: 311-314.

HÄRKÖNEN, T. 1986. Guide to the otoliths of the bony fishes of the Northeast Atlantic. Danbiu ApS, Hellerup, Denmark. 
HAUG, T., H. GJØSÆTER, E. NORD $\varnothing Y$ and T. SCHWEDER. MS 1992. A research proposal to evaluate the ecological importance of minke whales Balaenoptera acutorostrata in the Northeast Atlantic. ICES CM Doc., No N:8, 75 p.

HAUG, T., H. GJØSÆTER, U. LINDSTRØM and K.T. NILSSEN. 1995a. Diets and food availability for northeast Atlantic minke whales Balaenoptera acutorostrata during summer in 1992. ICES J. Mar. Sci., 52: 77-86.

HAUG, T., H. GJØSÆTER, U. LINDSTRØM, K.T. NILSSEN and I. RØTTINGEN. 1995b. Spatial and temporal variations in northeast Atlantic minke whales Balaenoptera acutorostrata feeding habits. In: Seals, whales, fish and man, A.S. Blix, Ø. Ulltang, and L. Walløe (eds.), Elsevier Science B.V., p. $225-239$.

HAUG, T., U. LINDSTR ØM, K.T. NILSSEN and I. RØTTINGEN. 1996. Diet and food availability for northeast Atlantic minke whales Balaenoptera acutorostrata. Rep. Int. Whal. Comm., 46: 371-382.

HORWOOD, J. 1990. Biology and exploitation of the minke whale. CRC Press, Inc. Boca Raton, Florida.

HYSLOP, E.J. 1980. Stomach content analysis - a review of methods and their application. J. Fish Biol., 17: 411-429.

ICHII, T. and H. KATO. 1991. Food and daily food consumption of southern minke whales in the Antarctic. Polar Biol., 11: 479-487.

JONSGÅRD, Å. 1951. Studies on the little piked whale or minke whale (Balaenoptera acutorostrata Lacépède). Norsk Hvalfangsttid., 40: 209-232.

1966. The distribution of Balaenopteridae in the North Atlantic Ocean. In: Whales, dolphins and porpoises, K.S. Norris (ed.), University of California Press, Berkeley and Los Angeles, p. 114-124.

1982. The food of minke whale (Balaenoptera acutorostrata) in northern North Atlantic waters. Rep. Int. Whal. Comm., 32: 259-262.

KAWAMURA, A. 1980. A review of food of Balaenopterid whales. Sci. Rep. Whales Res. Inst.,
Tokyo, 32: 155-197.

MÅRTENSSON, P.E., E.S. NORDØY and A.S. BLIX. 1994. Digestability of krill (Euphausia superba and Thysanoessa sp.) in minke whales (Balaenoptera acutorostrata) and crabeater seals (Lobodon carcinophagus). Brit. J. Nutr., 72: 713-716.

NORDØY, E.S. and A.S. BLIX. 1992. Diet of minke whales in the Northeastern Atlantic. Rep. Int. Whal. Comm., 42: 393-398.

NORD ØY, E.S., W. SØRMO and A.S. BLIX. 1993. In vitro digestability of different prey species of minke whales (Balaenoptera acutorostrata). Brit. J. Nutr., 70: 485-489.

ØEN, E.O. 1995. A Norwegian penthrite grenade for minke whales: Hunting trials with prototypes and results from the hunt in 1984, 1985 and 1986. Acta vet. scand., 36: 111-121.

ØIEN, N. 1988. Length distributions in catches from the northeastern Atlantic stock of minke whales. Rep. Int. Whal. Comm., 38: 289-295.

1991. Abundance of the northeastern Atlantic stock of minke whales based on shipboard surveys conducted in July 1989. Rep. Int. Whal. Comm., 41: 433-437.

OLSEN, M.A., T.H. AAGNES and S.D. MATHIESEN. 1994a. Digestion of herring by indigenous bacteria in the minke whale forestomach. Appl. Environ. Microbiol., 60: 4445-4455.

OLSEN, M.A., E.S. NORD $\varnothing$ Y, A.S. BLIX and S. D. MATHIESEN. 1994b. Functional anatomy of the gastrointestinal system of north-eastern Atlantic minke whales (Balaenoptera acutorostrata). J. Zool., London 234: 55-74.

PIERCE, G.J. and P.R. BOYLE. 1991. A review of methods for diet analysis in piscivorous marine mammals. Ocean. Mar. Biol., Ann. Rev. 29: 409-486.

SKAUG, H.J., H. GJØSÆTER, T. HAUG, U. LINDSTRØM and K.T. NILSSEN. 1997. Do minke whales Balaenoptera acutorostrata exhibit particular prey preferences? J. Northw. Atl. Fish. Sci., 22: 91-104 (this volume). 